\title{
Measurement and Evaluation of Exhaust Emissions from Diesel Railcars
}

\author{
Ichiro HAGA \\ Senior Researcher, \\ Koichi MURAKAMI \\ Senior Researcher, \\ Drive Systems, Vehicle Control Technology Division \\ Shinichi MAEHASHI \\ Researcher, \\ Drive Systems, Vehicle Control Technology Division
}

Hideo NAKAMURA

Senior Researcher,

\begin{abstract}
Understanding actual exhaust emissions is important in executing appropriate measures to reduce them. To this end, we developed an exhaust emission measurement technique that can be executed relatively easily using engine bench test boards at JR rolling stock maintenance depots and in diesel railcars under running conditions. We also clarified the current status of exhaust emissions according to the results of measurement.

Additionally, we investigated a number of the operation modes in commercial trains, and proposed the test cycle concept which was applied to evaluation of measurements based on the analysis results.
\end{abstract}

Keywords: diesel railcar, diesel engine, exhaust emissions, NOx, test cycle

\section{Introduction}

No pertinent exhaust emission regulations applicable to railway vehicles equipped with engines are currently available in Japan. Accordingly, opportunities to measure exhaust emissions from the engines of such vehicles are significantly limited. However, it is essential to grasp the current status of exhaust emissions for the appropriate implementation of measures to deal with them. For this purpose, a way to measure exhaust emissions relatively easily at JR rolling stock maintenance depots (referred to here as JR railcar depots) is needed.

To this end, we investigated a method of measuring exhaust emissions in accordance with existing regulations intended for large-sized automobiles. In addition, we developed a technique that can be used to measure exhaust emissions using engine bench test boards (referred to here as bench test boards) at JR railcar depots and on diesel railcars under running conditions with relative ease. Substantial exhaust emission measurement was carried out using this method under these conditions. We also investigated the operational frequency of different notches and each region of engine speed under running conditions with many commercial trains, and used the test cycle concept developed to evaluate the measurements based on the analytical results. This report describes the development of the exhaust emission measurement method and the approach to evaluating diesel railcars.

\section{Regulation and measurement of automobile exhaust emissions [1]}

Exhaust emission regulations applicable to automobiles specify components and limit values of exhaust emissions for control subjects and test procedures. In general, NOx (nitrogen oxide), $\mathrm{CO}$ (carbon monoxide), HC (hydrocarbon) and PM (particulate matter) are specified as con- trol subjects for diesel-powered automobiles in terms of exhaust emissions. Large-sized automobiles are examined through a bench test board in the engine unit, and the unit of $\mathrm{g} / \mathrm{kWh}$ is used to express limit values.

The test cycle of bench test boards has a steady-state procedure and a transient procedure. The cycle in the steady-state mode is characterized by each test mode (engine speed and load factor) and the weighting factor for the results of measurement for each mode. The transient mode test cycle is characterized by a running pattern that repeats acceleration, deceleration, stopping, etc.

\section{Measurement of exhaust emissions from railway vehicles}

Since it is difficult to perform measurement of exhaust emissions from railway vehicles using a chassis dynamometer, it is appropriate to perform such measurement using an engine dynamometer in the same way as for largesized automobiles. Accordingly, we designed a method of measuring exhaust emissions that can be executed using an bench test board at a JR railcar depot. This method must allow the related equipment to be set up and removed readily, and an appropriate level of accuracy must be ensured. As it is inefficient to remove engines from railway vehicles only for the purpose of exhaust emission measurement, we designed a measurement method that can be executed on diesel railcars under running conditions.

\subsection{Development of an exhaust emission sampling method}

Exhaust emissions must be sampled from exhaust pipes to enable their measurement. Accordingly, we developed a sampling adaptor that removes the need to remodel the existing exhaust pipe and is easy to install (Fig. 


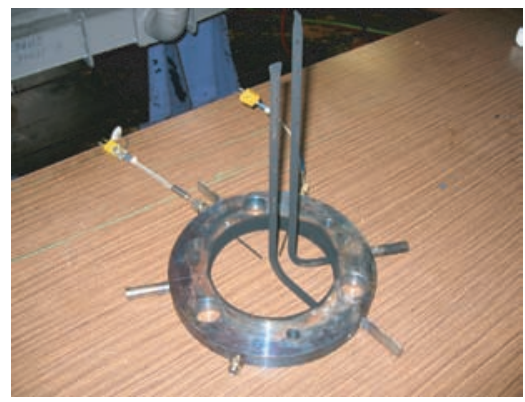

Fig. 1 Sampling adaptor

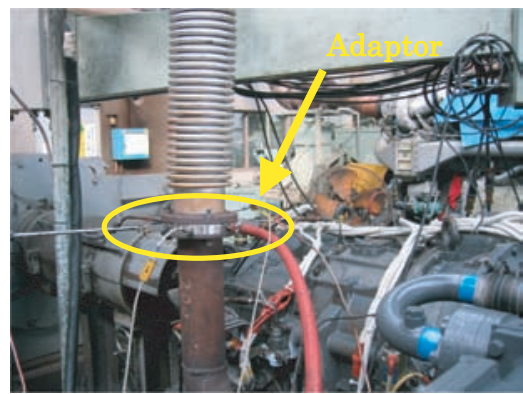

Fig. 2 Adaptor installation method

1). It is fitted to the flange joint of the exhaust pipe, and has many sampling intakes and installation seats to accommodate sensors for temperature, pressure, etc. Figure 2 shows the installation method. Exhaust emissions are channeled from this adaptor to an exhaust emission measuring instrument through a specially designed hose.

\subsection{Problems in calculation processing of exhaust emission measurements}

\subsubsection{Atmospheric correction}

NOx concentration is corrected to a standard value as it is easily influenced by humidity and temperature [2]. We measured NOx concentration under a variety of atmospheric conditions using an RTRI bench test board through over a period of one year with the same engine and the same driving conditions. Figure 3 shows the results of the measurement. The NOx concentration varied greatly before correction despite the identical driving conditions, but the values after correction were roughly the same, thereby confirming the necessity and effectiveness of correction.
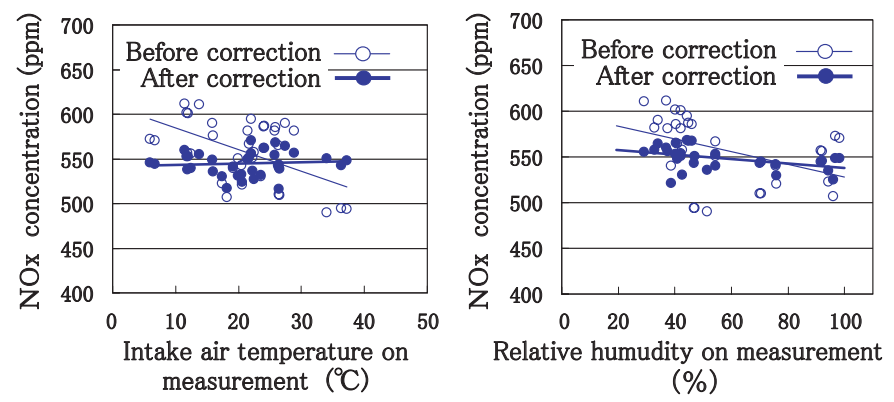

Fig. 3 Comparison before and after humidity and temperature correction

\subsubsection{Method of calculating total exhaust gas mass flow rate}

Measurements taken by the exhaust emission measuring instrument are generally indicated as a volume concentration (ppm, etc.), but the exhaust emission regulation values are indicated in terms of specific emissions $(\mathrm{g} / \mathrm{kWh})$. The calculation of specific emissions from volume concentration therefore requires data on the exhaust gas mass flow rate $(\mathrm{kg} / \mathrm{h})$ and engine output power $(\mathrm{kW})$. Ascertaining the value of the exhaust mass flow rate $(\mathrm{kg} /$ h) requires data on the total exhaust mass flow rate, but direct measurement of this variable is very difficult in large-scale diesel engines.

Accordingly, we conducted a comparative study of the three methods outlined with an RTRI bench test board using Total exhaust gas mass flow rate $=$ intake air mass flow rate + fuel mass flow rate $(\mathrm{kg} / \mathrm{h})$ to indirectly calculate the total mass flow rate of exhaust gas.

(1) Method involving measurement of airflow velocity at the intake air pipe

This method involves measuring airflow velocity by setting up a small anemometer in the center of the intake air pipe and calculating the mass flow rate of air intake using values for the density of air and the pipe's sectional area. However, intake air is often taken directly from the engine intake in measurement with bench test boards at JR railcar depots. Moreover, remodeling of the intake system is required for measurement on diesel railcars. Anemometer installation in both cases is therefore considered difficult.

(2) Method involving measurement of supercharged-air temperature and pressure

This method involves calculating the density of supercharged air using temperature and pressure measurements in the intake manifold of the engine, and calculating the mass flow rate of intake air using the nominal cylinder volume and the engine speed. It is necessary to set up a plug for sensor installation in the intake manifold, but measurement using this technique is otherwise relatively easy.

(3) Carbon balance method

The carbon balance method involves calculation is based on the principle that the total number of carbon atoms between at the entrance of the engine (intake air + fuel) and at the exit (exhaust emissions) are the same. As the addition of a measuring instrument and sensor is unnecessary, the technique is comparatively easy, though it also requires the measurement of $\mathrm{CO}_{2}$ concentration.

From a comparative study of these approaches, we concluded that the carbon balance method was the best because it offers the easiest measurement. Accordingly, this technique was adopted for bench test boards at JR railcar depots and measurement on diesel railcars.

\subsection{Measurement of PM}

PM is a term used in this paper to describe particulate matter in exhaust emissions, including grime. In the measurement of PM, a sampling filter adsorbs exhaust emissions cooled below a regular temperature using air through a dilution tunnel. The PM exhausted causes a 


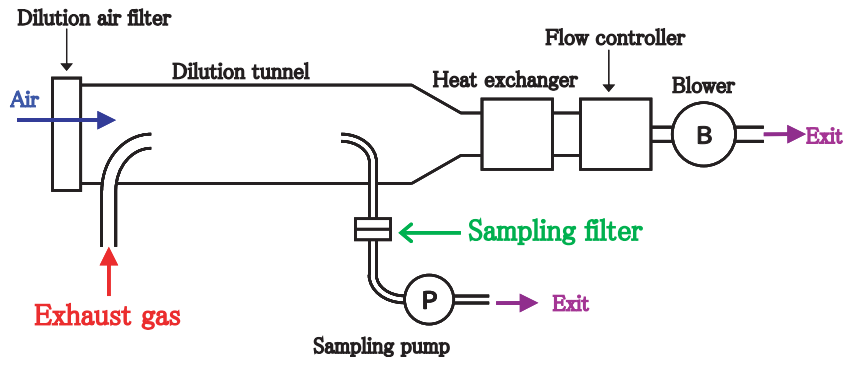

Fig. 4 PM measurement method

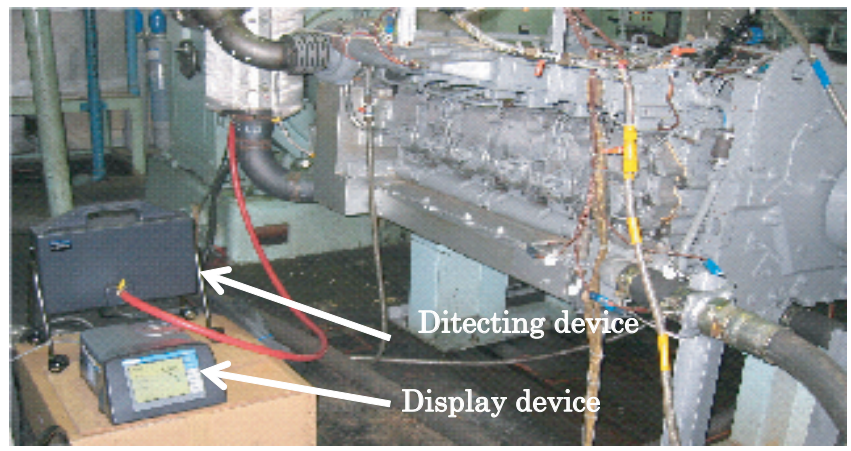

Fig. 5 Opacimeter

weight difference in the sampling filter before and after measurement, and this difference is taken as the PM amount (Fig. 4). As it is difficult in large-scale engines to dilute all exhaust emissions, a dilution and partial treatment mechanism is required. The need for such a specialized device means that PM measurement is difficult in JR railcar depots, so we assumed measurement of exhaust gas smoke emissions using an opacimeter as an alternative (Fig. 5). The opacimeter measures smoke concentration from the light intensity that attenuates when light passes exhaust gas.

\section{Results of exhaust gas measurement according to the technique developed}

We executed exhaust emission measurement of seven types engines for diesel railcar using the technique outlined above with bench test boards at RTRI and JR railcar depots. In addition, we evaluated the results of measurement using existing test cycles. These test cycles were the $\mathrm{F}$ cycle provided in ISO 8178-4 as specified by UIC exhaust emission regulations for railway vehicles, the $\mathrm{C} 1$ cycle provided in ISO 8178-4 as specified by EU exhaust emission regulations for railway vehicles and the D13M cycle specified by Japan's new short-term restrictions for large-sized diesel automobiles. All of these are steadystate mode cycles (Fig. 6).

It was clarified from the measurements that differences by engine type tended to be roughly equal regardless of the test cycle. Moreover, the specific emissions of NOx were almost equal for all engine types. On the other hand, the specific emissions of $\mathrm{CO}$ were large at the engine speed of low; therefore it can be said that the specific emissions of $\mathrm{CO}$ are larger for the D13M cycle with the mode at the engine speed of low than other cycles.

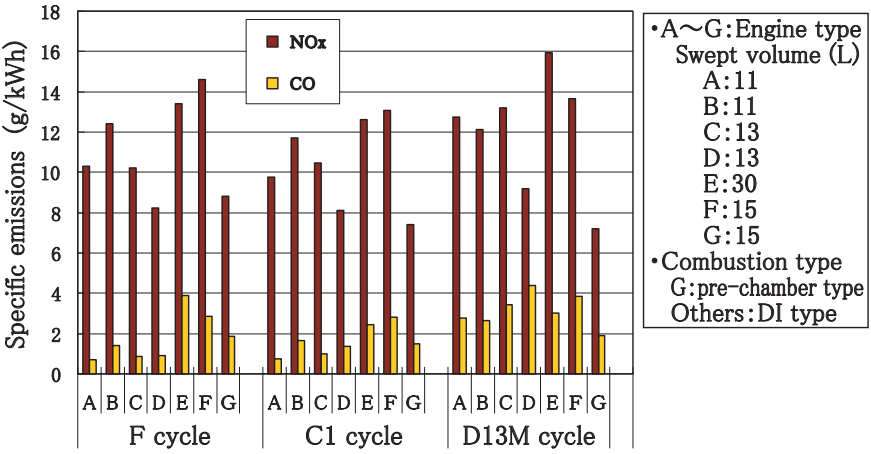

Fig. 6 Result of measuring exhaust emissions from diesel railcar engines

\section{Preparation of test cycles for diesel railcars}

It is important in test cycles that the results of measurement involving various engines for diesel railcars are objectively appreciable by the same standards. A test cycle has a transient mode and a steady-state mode, but the transient mode test cycle requires a bench test board equipped with a special controller. Therefore a steadystate mode test cycle is appropriate for diesel railcars. Moreover, it is important that the driving conditions and weighting factor of the test cycle reflect the state of diesel railcars in a state of running, such as notches with high operation frequency and an engine speed range at the use of ratio of high. Accordingly, we investigated the states of notches, vehicle speeds, engine speeds, etc. in a JR diesel railcar under running (referred to here as driving data) and developed a test cycle for diesel railcars based on the results of this investigation.

\subsection{Investigation of driving data for diesel railcars}

We investigated JR Hokkaido limited express vehicles and JR Kyushu rapid-transit vehicles, carrying out measurement on the amount of more than 100 trains in commercial operation. The collected information was processed as follows:

(1) Data was classified in percentage for each train according to the notch and usage region of each engine speed.

(2) The data collected from JR Hokkaido were independently classified in the Kiha 281 type (three trains) and the Kiha 283 type (two trains), thereafter a simple average of the two results was calculated.

(3) The data collected from JR Kyushu were independently classified in the Omura and Nagasaki lines, the Hohi line and the Kyudai line, thereafter a simple average of the three results was calculated.

(4) Finally, a simple average of the data from Hokkaido and Kyushu was calculated.

(5) Data according to notches were converted into data for the load factor of torque conversion (the highest notch was assumed to be $100 \%$ ), and was also converted into the load factor at intervals of $20 \%$.

(6) The engine speed was classified in the intervals of $200 \mathrm{rpm}$. 


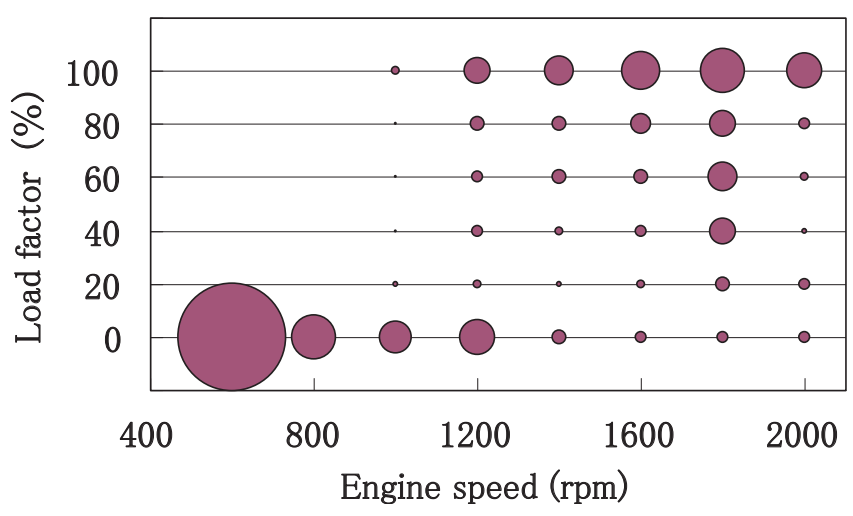

Fig. 7 Analysis of driving data in commercial operation

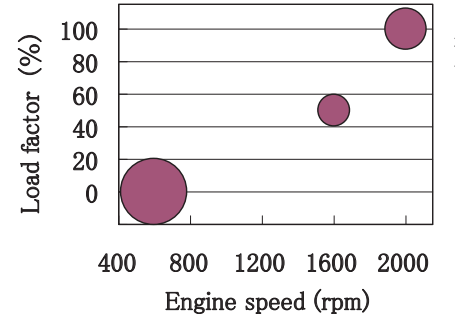

F cycle

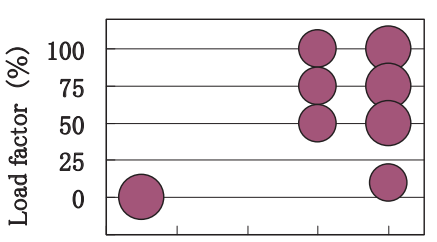

$400 \quad 800 \quad 1200 \quad 1600 \quad 2000$ Engine speed (rpm)

C1 cycle

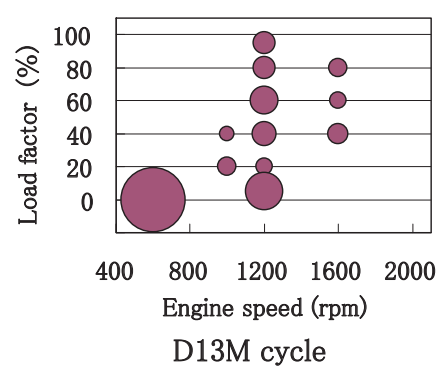

Fig. 8 Three existing test cycles

Figure 7 shows the driving data in commercial operation total results according to the usage region of the load factor and the engine speed. The figure does not include data for stop conditions. The size of each circle shows the operation frequency, and idling is represented by a load factor of $0 \%$. Figure 8 also shows the three existing test cycles. The circle position shows the test mode, and the circle size shows the weighting factor. The weighting factor is used for calculation of specific emissions in each test cycles.

The results of the investigation indicate that the operation frequency of high notches and idling is high, and show the differences at the three existing test cycles.

\subsection{Test cycle development}

\subsubsection{Basic concept}

We proposed a test cycle for diesel railcars based on the results of the investigation in consideration of the following points:

(1) The results of the investigations for operation data should be reflected as much as possible.

(2) The number of test modes should not be increased. In particular, including a test mode other than confirmation of regular performance with the bench test board should be avoided as much as possible.

(3) We should use the bench test data in the verification.

\subsubsection{Test cycle concept}

Table 1 and Fig. 9 show four concepts for the test cycle proposed from the tally a result of driving data. The circle size shows the weighting factor of each test mode. Figure 10 also shows the total results of the exhaust rate for $\mathrm{NOx}$ and $\mathrm{CO}$ from the engine of two types totaled using existing test cycles ( $\mathrm{F}$ and $\mathrm{C} 1$ ). In addition, Fig. 10 shows the tally a result for the four test cycle concepts introduced here. Here, the "All mode total" in the figure means that the measurement results for all modes of each en-

Table 1 Test cycle concepts

\begin{tabular}{|c|c|c|c|c|}
\hline \multirow{3}{*}{ Idea } & Mode & $\begin{array}{c}\text { Engine speed } \\
(\mathrm{rpm})\end{array}$ & $\begin{array}{c}\text { Load } \\
\text { factor } \\
(\%)\end{array}$ & $\begin{array}{c}\text { Weighting } \\
\text { factor }\end{array}$ \\
\hline \multirow{4}{*}{ A } & 1 & Low idle & - & 0.568 \\
\cline { 2 - 5 } & 2 & 1400 & 100 & 0.078 \\
\cline { 2 - 5 } & 3 & 1600 & 100 & 0.123 \\
\cline { 2 - 5 } & 4 & 1800 & 100 & 0.159 \\
\hline & 5 & 1800 & 60 & 0.072 \\
\hline \multirow{4}{*}{ B } & 1 & Low idle & - & 0.568 \\
\cline { 2 - 5 } & 2 & 1200 & 100 & 0.049 \\
\cline { 2 - 5 } & 3 & 1400 & 100 & 0.069 \\
\cline { 2 - 5 } & 4 & 1600 & 100 & 0.109 \\
\cline { 2 - 5 } & 5 & 1800 & 100 & 0.141 \\
\hline \multirow{4}{*}{ C } & 6 & 1800 & 60 & 0.064 \\
\cline { 2 - 5 } & 1 & Low idle & - & 0.568 \\
\cline { 2 - 5 } & 2 & 1200 & 100 & 0.058 \\
\cline { 2 - 5 } & 3 & 1400 & 100 & 0.082 \\
\cline { 2 - 5 } & 4 & 1600 & 100 & 0.127 \\
\hline \multirow{3}{*}{ D } & 5 & 1800 & 100 & 0.165 \\
\cline { 2 - 5 } & 2 & Low idle & - & 0.568 \\
\cline { 2 - 5 } & 3 & 1400 & 100 & 0.094 \\
\cline { 2 - 5 } & 4 & 1600 & 100 & 0.147 \\
\hline & & & 100 & 0.191 \\
\hline
\end{tabular}
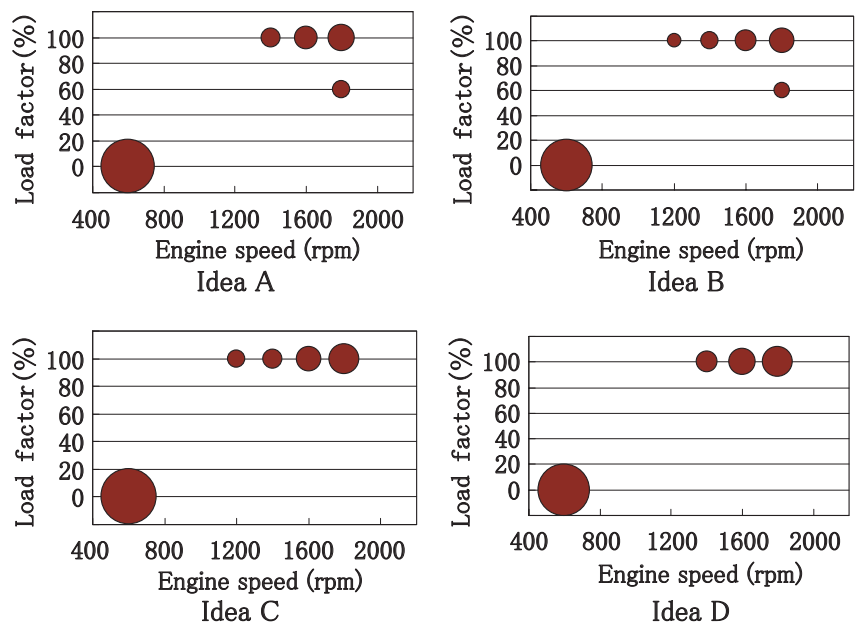

Fig. 9 Test cycle concepts 

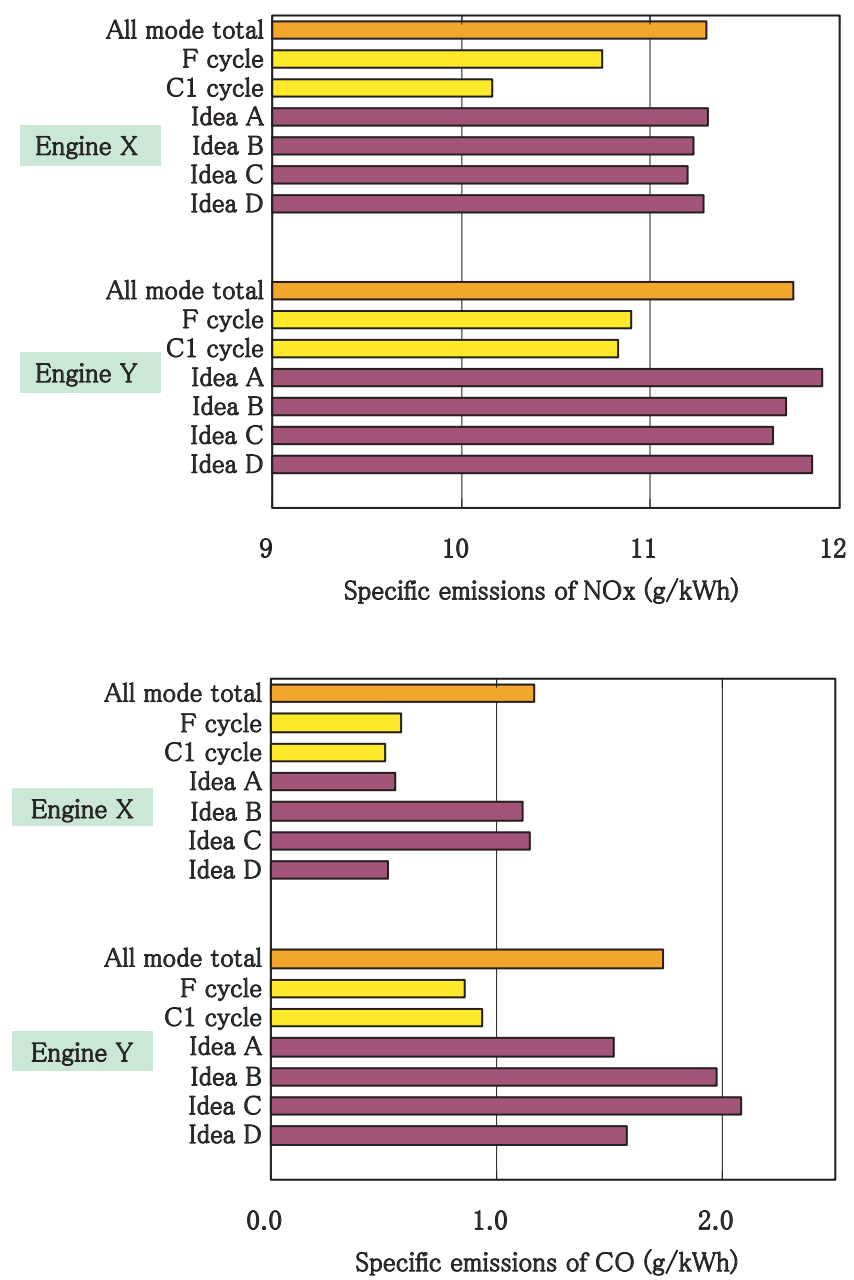

Fig. 10 Evaluation by each test cycle

gine were the tally result of driving data (Fig. 7). If the total result using the test cycle is near the "All mode total" value, it can be said that the test cycle concept shows the actual conditions.

Figure 10 shows that evaluation reflecting reality can be performed more accurately by using the test cycle concept proposed here than existing test cycles.

\section{Conclusion}

(1) An exhaust emission measurement technique that can be executed relatively easily using bench test boards at JR railcar depots and under diesel railcar running conditions was developed in this study.

(2) Exhaust emissions in seven types of engines for JR diesel railcars were measured with a bench test board using the technique developed. In addition, the results of measurement were evaluated using existing test cycles.

(3) Driving data from JR diesel railcars was investigated, and the test cycle concept proposed here was used to evaluate exhaust emission measurements made based on the results of the investigation. It was found that using this test cycle concept enabled exhaust emissions evaluation that was nearer to the actual conditions than the case of using existing test cycles.

This report describes the design of an exhaust emission measurement technique that can be executed relatively easily at JR railcar depots, and outlines the development of a method to evaluate exhaust emissions that matches the actual conditions of JR diesel railcars.

In the future, we will include research on a simple measurement method for PM, measures to reduce exhaust emissions for diesel railcars, and study a test cycle for diesel-locomotive engine examination.

\section{References}

[1] Murakami, K., Haga, I., Nakamura, H., "Trend of Exhaust Emission Regulations," RTRI Report, Vol. 19, No. 5, pp. 51-56, 2005 (in Japanese).

[2] JIS B 8008-1, Reciprocating internal combustion engines -Exhaust emission measurement- Part 1: Testbed measurement of gaseous and particulate emissions, 2009. 